\title{
Exhaustion and scepticism within the scientific community: the case of women scientists and their peers in India
}

\author{
Cheshta Arora
}

The article examines the discourse of 'women in science' in India, its tendencies to focus on the linear relation between women, science and development and its emphasis on 'increasing the number of women in science'. By doing so, the paper argues that this emphasis produces two predominant experiences - exhaustion and skepticism - among the scientific work-force in India. It offers an ethnographic account of these two affects and argues that closer attention to such experiences can contribute to the discourse of 'women in science', which is caught between failures and achievements of women scientists in India.

Keywords: Development, exhaustion, gender, scepticism, women in science.

IN the October 1935 issue of Current Science ${ }^{1}$, one finds an anonymous entry under the 'Letters to the Editor' section. It reviews the 1894 book Man and Woman by Havelock Ellis ${ }^{2}$. This is the first reference to the problem of sexual difference in the journal. While reviewing the 1894 book, the authors conclude:

'...it seems fairly certain that women are not going to outstrip men or even to equal them, in the fields in which men are certainly successful. ${ }^{1}$,

'...the facts of physical and psychical organization of women have a profound practical bearing on the sphere of activity into which they are entering in increasing numbers. They are an important industrial factor, although large portion of them may not remain as life-workers. Apparently, as a sex, they seem to lack both a man's ambition and his disinterested mental curiosity. Because of the possible transitoriness of their engagements, it is difficult to estimate the force and soundness of their disposition to be trained for skilled and responsible positions' [emphasis added].

It is after 60 years that one finds another item under the 'News' section of the same journal that mentions the problem of gender difference and its relation with science $^{3}$. It reports the minutes of a panel discussion on 'Identifying obstacles to successful careers for women scientists', which took place at the 16th International Congress of Biochemistry and Molecular Biology at New

Cheshta Arora is in the School of Social Sciences, National Institute of Advanced Studies, IISc Campus, Bengaluru 560012 , India and Manipal Academy of Higher Education, Manipal 576 104, India.

e-mail: cheshta@nias.res.in
Delhi in 1994. While presenting the minutes, the author emphasizes on three points ${ }^{3}$. First, the striking similarity between the United States, Germany and India vis-à-vis the condition of women scientists. Second, while reporting in detail regarding the opinions of the second women speaker, the author notes that the speaker

'...represented more or less the government of India viewpoint, especially so regarding the upliftment of women in general in this country, including that of rural women. She spoke about the consideration of several facilities to make it more feasible for women scientists to pursue their career. Since women do have to take care of household responsibilities, including child-bearing' [emphasis added].

Third, the author notes a male scientist to have mentioned that the '...scientific capabilities of men and women are different and only a few women scientists are motivated enough to achieve outstanding results', repeating the conclusions of the anonymous 1935 paper.

I take the liberty to quote in detail from these two papers because the points mentioned here regarding the problems of women in science continue to haunt the discussions on the issue in other articles in the journal that follow these two. The frequency of papers published in Current Science on this particular topic continuously increased after the second paper published in 1995. This is expected, since the dismal number of women in the labour force in general and as scientific workforce in particular is a matter of concern for policy-makers in India. It is important to note that the papers published post-1995 are markedly different from the opinion of the anonymous 1935 paper, in the sense that post-1990s, authors 
publishing in Current Science on the issue of women in science focus more on gender difference embedded in social conditions than on biological difference. Thus, the explanation moves from 'physical and psychical organization of women' to 'household responsibilities'. Family and social roles imposed on women continue to explain the dismal number of women scientists. The discussions on the issue are mostly published under 'News', 'Correspondence', or 'General Article' section of Current Science $^{4-9}$ and as research articles elsewhere ${ }^{10}$. The discourse shifts slightly in 2010, after 15 years, where a major research study analysed data from 500 women to point towards systemic biases that operate at the organizational level as a significant contributing factor ${ }^{11}$. This publication shifted the focus from general societal attitudes affecting the participation of women to flaws inherent in the organizational structure, values, and policies. However, since the publication of the above-mentioned article $^{11}$, the discussion of 'women in science' in Current Science is limited by this specific and narrow framing between societal attitudes versus organizational responsibility and a sole focus on 'numbers' makes the discourse stagnant.

Drawing from eight months of ethnographic research in an autonomous scientific research organization in Bengaluru, Karnataka and the largest Indian software multinational firm (henceforth, organizations $\mathrm{A}$ and $\mathrm{B}$ respectively), the aim of this article is to suggest that a focus on certain 'affects' circulating in the scientific community vis-à-vis 'women in science' has the potential to interrupt the discourse and interrogate the hegemonic premises vis-à-vis science, allowing one to open it to new possibilities. I use 'affects' to distinguish it from wellarticulated statements that are generated through interviews. Affect is that which is felt, but at the same time the 'feeling' depends on the 'angle of our arrival', felt from a specific point ${ }^{12}$. The interview statements analysed here are not presented as self-evident, empirical statements, but are subjected to critical discourse analysis that interrogates the social, linguistic and cultural presuppositions $^{13}$.

I intend to show that the problematic of 'women in science' cannot be resolved by simple additive policy measures that focus on merely increasing the representation of women in scientific organizations. This point is well made in feminist science studies scholarship. However, I bring to the fore the 'exhaustion' felt by women scientists in India vis-à-vis not just the exclusionary nature of scientific practice, but also the discourse of 'women in science' in its current form. Thus, the paper foregrounds the need to counter not just the scepticism of the conservative scientists who act as gatekeepers, but also the necessity to learn to register the 'exhaustion' of the working women scientists who are caught between the political emphasis on women's participation in science and hierarchies of science. The dominant approach in the field of 'women in science' in India theorizes certain processes in scientific practices as 'gendered exclusion', 'glass ceiling' and 'plateaus'. While such articulations mark the exclusionary nature of scientific practice to make the case for more women in science, they limit the meaning of 'scepticism' and 'exhaustion'. Inadvertently, it falls on reductive notions of 'gatekeeping' and 'exclusion', erasing the over-determined nature of such articulations and experiences. This article, however, interprets 'exhaustion' and scepticism as affects that are produced not just by the exclusionary nature of science, but by the discourse of 'women in science' that finds legitimacy in existing valuations that equate participation in science with (balanced) development and empowerment. Thereby failing to interrogate the system that evaluates knowledge, labour and bodies that give science its authority. This article treats 'exhaustion' and 'scepticism' as not just symptoms of exclusionary scientific practices, but a symptom of the discourse of 'women in science' itself, as Subramaniam ${ }^{16}$ has argued elsewhere in the context of the United States. Critiquing the metaphors of 'leakages' and 'pipes' that circulate in the women in STEM (science, technology, engineering and mathematics) discourse, Subramaniam ${ }^{16}$ writes:

'Initiatives in the sciences (such as represented by the women in science policies) have historically been dominated by strategies to include women (that) have been governed by uninspired, regimented, and conformist notions about the conditions that foster a career in science...Imagining the regimented travels in pipes that give the travellers no agency in their journey, we might start cheering for the leaks and for those who escape the drudgery of pipe travel'.

This paper, thus, draws from various ethnographic accounts from the field that show the limits of the current discourse of 'women in science' and its dominant premises.

\section{'Women in science': between the politics of numbers and balanced development}

\section{Balanced development}

A report on the status of women scientists in Asia begins with the following truth claim: 'utilizing women's talent in science and technology is crucial for sustainable development ${ }^{17}$. Another report relying on this truth claim, discusses the challenges faced by women scientists in India and the steps taken by the Government to mitigate these challenges ${ }^{18}$. The authors argue that 'mainstreaming gender is important not just to make sure that women get a chance to give expression to their creativity and abilities but also because it is essential for the balanced 
development of any society ${ }^{18}$ [emphasis added], using the adjectives 'balanced' and 'sustainable' interchangeably.

The axiom performs an ideological gesture. By linking individual creativity with its role in maintaining the balance of society, not only does it suggest that a career in science is about individual creativity and expression, but also that by stimulating creativity and expression of individual women scientists one can achieve balanced development, or sustainable development of the society at large. Thus, against the harmony of nature and society, proposed by the conservative Indian scientists, the authors $^{18}$ offer another yet similar vision that relies on notions of balance and harmony. Two claims implicit in the statement are of interest here. First, that balanced development is achievable. Second, women's creativity and expression should have an additional value, i.e. a balanced development of society to be considered worthy of attention. This truth claim is not unique to this report, but guides, informs and influences both Government policies around 'women in science' in India and feminist science activism that wants to increase the number and visibility of women in STEM fields. Thus, a not so obvious relation between the two conceptual categories 'women/ science' is as follows:

\section{Women + Science $\rightarrow$ (Balanced) Development.}

It incorporates within itself a particular scalar and temporal logic. Temporally, it freezes and takes for granted the linear movement of time, reaffirming the faith in a gradual movement towards more progressive, developed and inclusive society. With such a formulation, anyone rejecting the necessity of gender equality is automatically denying the necessity of balanced development (or vice versa) and the march of humanity towards an inclusive and progressive society. The diagram also performs a scalar arrangement, wherein the two scales 'body' and 'society' - are constituted and arranged hierarchically, where the 'body' (of the woman) and 'knowledge' are subordinate and in sync with an abstract entity called 'society', which is to be developed in 'balance'. The problem of 'women in science' is necessarily plugged into the linear trajectory of balanced development which limits the discourse to one particular kind of temporal and scalar arrangement. This hinges the value of women's work to an abstract politics of development.

\section{The politics of numbers}

A 1974 report made visible the dismal economic condition of Indian women in all spheres of activity ${ }^{19}$. Later, another report explicitly noted the dismal condition of women in formal and informal labour ${ }^{20}$. These two reports relied on numbers and quantitative methods to make a certain lack visible to the concerned authorities. Following this tradition of feminist critique, the discourse of 'women in science' in India began after the meagre number of women in science became apparent and a matter of concern in a post-liberalized economy.

Reality presented in the form of 'facts', however, is an important point of contention between those from science disciplines and those from social sciences, presumably 'non-scientific' disciplines. It is often contested whether facts are self-evident and merely discovered by a scientist-subject, or they are constructed amidst a hybrid alliance. For instance, to construct the 'fact' of less number of women in science, a feminist social scientist subject has to necessarily distinguish between scientific and non-scientific activity. All entities - including women engage in various kinds of activities. However, it is only when some activities are deemed 'scientific' that the 'fact' of less number of women in science gains value and currency. Similarly, a scientific organization can present a 'fact' that $30 \%$ of its scientific workforce consists of women suggesting that the organization is closer to a diverse work-culture, if gender equality is measured quantitatively. However, this fact can also come to mean a different reality, wherein a more nuanced analysis can suggest that most women out of that $30 \%$ are engaged in lower to mid-level skills, whereas the high-level skills and decision-making are still controlled by male scientists in the organization - suggesting a scientific institution built on hierarchical labour relations that cut across gender, as well as other differences.

The scholarship on women in science has successfully served to visiblize and interrupt the social ${ }^{21,22}$. However, an over-reliance on participation represented through numbers can also limit the multiplicity inherent in the field. Policy initiatives and scholarship emerging from 'women in science' thus foreclose 'women' as a homogeneous group that can be counted and is empirically available for targeted policy action. As a homogeneous group and a policy target, only two kinds of narratives are then made available to women scientists working in an organization - a narrative of gender-bias or a narrative of success and achievement, a narrative of participation or exclusion. This results in multiple erasures of other narratives, experiences and critiques. The scholarship coming out of the 'women in science' discourse mostly deploys surveys and formal, structured and unstructured interviews relying on large sample size to make the point. Few studies have used qualitative social science methodsthat include intensive field-work and deploy interpretive, phenomenological, discursive approaches to make sense of the field.

The book titled 'Leelavati's Daughters ${ }^{, 23}$ is an example of how government initiatives turn 'women scientists' into a homogenous, one-dimensional object. It presents only one kind of women scientists - the achievers, who desired and achieved despite all odds. The book is 
critiqued by feminist scholars for its aforementioned onedimensional approach to the problem of women scientists. They argue that it excludes women who could not make into the scientific field, the ones left behind implying that their failure was not individual but structural. To focus on exclusions and how they structure an institution is an important critique, and a good starting point to rethink the problem of women, gender and science, and the adequate responses to the same. However, the aforementioned critique also becomes guilty of the same mistake wherein the problem of 'women in science' is again understood through the concerns of success and failures.

There are two kinds of scholarship coming out of the 'women in science' discourse. The first kind communicates through conference proceedings and journal articles written by a few articulate scientists bringing to light the problems, necessities of policy interventions and the immediate policy responses necessary to address the problem. An emphasis on numbers and an association between gender diversity in scientific workforce, balanced development and creative expression of women is stronger in this scholarship. The second kind is written by women studies scholars on the problem of women in science that draws attention to the values predominant in scientific organizations with the hope that scientific practice will be rethought ${ }^{24-26}$. Both scholarships, however, hinge their argument on obstacles, values and practices that hinder women or other minority groups from entering and participating in the existing scientific organizations. This paper complements this scholarship by interrogating the emphasis on 'participation', the conditions that make it possible and the discursive association between participation, desire, autonomy and empowerment that is predominant in the field. Next, we consider the ethnographic experience to account for two affects exhaustion and scepticism-resulting from the current focus of 'women in science' discourse on development and representation.

\section{A brief note on the methodology}

This article aims to take a different approach than that which is usually adopted. It uses ethnographic data to consider current discourse of 'women in science' and the policy responses emergent from it. For this study, ethnographic methods such as informal conversations, participant observations and engagement with the participants, their work and life were used. These are common methods adopted by organization studies scholars internationally. However, in India, there is a general lack of critical management/organization studies that use qualitative methods to study organizations. Due to this, managers and HR teams in Indian organizations are often suspicious of the presence of a social science researcher in the organization, which makes qualitative study of organiza- tions and their workforce difficult. However, it is still worthwhile to use qualitative methods despite resistance because they allow the researcher to capture affects, mood and opinions that do not emerge in quantitative methods such as surveys or formal interviews. This study used in-depth and formal interviews as a tool to navigate the two organizations which were otherwise suspicious of having a social science researcher for a long time. Interviews allowed free movement inside these organizations that otherwise have strict security rules that limit the movement of visitors. Additionally, four months of internship with the HR allowed access to the archives, the library, canteen, and offices and spaces that are otherwise closed to researchers. My normal day during the ethnographic study involved reaching the workplace in the morning to spend the entire work-day inside that allowed me to capture the rhythm of the two organizations. I was not involved with the everyday activities of the HR team of organization A, since the team was mostly responsible for back-end logistics. However, in organization B, the HR team was responsible for aggressively curating the workplace culture by organizing various events around issues such as environment, diversity, independence day, etc. and even conduct day-to-day activities around team-building, leadership, etc. This allowed a deeper engagement. As a post-positivist method, ethnographic experiences collected through such engagement should not be seen as representative of the field, but encounters that force one to think differently.

The two organizations under consideration in this study are an exception within the larger public and private sector enterprises in India. Both organizations boast of a relatively high number of women workforce, and have garnered much attention in the past year for their gender diversity and share similar narratives vis-à-vis their foundation. Both were founded in the 1960s, envisioned for a newly independent country harbouring ambitions to leapfrog into a developed, global power riding on the shoulders of scientific and technological development. Both had founding fathers who envisioned the two organizations single-handedly and boast of a 'diverse, open and equal' culture in the organization. However, they differ in one aspect. Organization A, which is an autonomous agency of the Government of India, has been working with a minimum amount of fanfare, and the workforce is characterized as 'modest' and 'quiet'. However, this has been changing in last few years as the organization has made its presence visible on social media platforms such as Facebook and Reddit. Organization B which has been revamping its image for Industry 4.0, explicitly boasts of implementing special policies for its women workforce, and is generally known for its emphasis on employee retention, good work culture and philanthropy. The larger character of each organization is important to describe in brief, as it impacts how its workforce represented itself during formal interviews and the subsequent necessity of 
participant observation. Most one-to-one interviews resulted in standard narratives, repeating the larger culture that the organization constantly boasts of in the media.

However, it is only by capturing the rhythm of the organization and its employees that one can observe ruptures in this standard narrative of aspiration, exhilaration and appreciation of the organization and its initiatives towards fostering equality. The ruptures, however, force one to register two other affects - 'exhaustion' and 'scepticism' - vis-à-vis organizational policies targeting women in science. Through the ethnographic account, we examine these two affects and their implication for the 'women in science' discourse.

\section{Circulation of 'women in science' discourse and its two symptoms encountered in the field}

\section{Scepticism}

'There are so many women in the organization now...'

It was during a conversation with Dr R, a senior-level scientist, in her early 50 s that the question of representation came up. $\mathrm{R}$ was quite satisfied with her career trajectory, was happy about the support that she had received from the organization in terms of childcare and had even climbed up the hierarchy. From her own experience, she believed that Government policies seemed to be working, as she saw so many women around her in the organization compared to the number in the early 1980s when she had first joined. On pointing out that it is just $30 \%$ of the total workforce, R pointed out that 'it can't be, the number should be higher, but anyway this is way more than what they had before'. I met R during my initial days of the fieldwork when I was still trying to understand the nuances of the field. R's narrative confirmed the standard one reported in the media about the organization. However, R's narrative is symptomatic of the way in which the discourse around equality and diversity circulates in the organization and media, which I argue results from certain limitations inherent in the discursive framework that emphasizes on participation. The association between women, participation and development produces a sense of individual merit ${ }^{27}$ among the scientists (both male and female) who have managed to climb up the hierarchy. Simultaneously, the organization appears as a benevolent entity through its 'gender-sensitive' policies, that 'enable them to maintain a work-family balance', as women scientists from organization A emphasized. The workfamily balance is presumed to be an absolute necessity for working women. However, hard work and sacrifice continue to be incentivized as "necessary for good scientific work', as is visible in the following remarks of a senior male scientist who also headed organization $\mathrm{A}$ and was responding to my observation that the organization has not had a woman director.
'Time is flexible. During my days, I have spent 16-20 hours in the organization; the nature of the work demands this. I even slept in my office. And I could do this because I had full support at home. Can you expect a woman to do so much? They have other responsibilities to fulfil.'

Thus, the observation that the organization has a good work-culture is emphasized side by side with a notion of hard work and sacrifice, justified by the nature of scientific work. This suggests that a mere emphasis on participation can go hand in-hand with the superiority and sacrifice mandated by science, a superiority which is not interrogated the moment the 'problematic' of 'women in science' is plugged with the increasing importance of science for development.

'I don't see why we need more policies for women...'

While R, who had seen days when the number of women in the organization was less, assumes that more number of women indicates a certain success of 'women in science' discourse and policy, one finds that this association between more numbers as being equivalent to more diversity gives way to a certain scepticism among young working women. This became more prominent during my fieldwork in organization B, where I actively worked with the HR team, had multiple conversations with the employees during lunch/tea hours and helped organize a panel discussion around diversity as part of the International Women's Day. As International Women's Day was approaching, I was given the responsibility of writing some questions for the Chair of the panel on 'diversity in IT'. The word 'diversity was used instead of women in IT because, as the HR noted, 'we've been focusing on women for a while now, I think we need to start focusing on other groups including men'. It is important to note that International Women's Day was used by her to make the case for diversity as such. However, the affect behind equating women with diversity resulted not from exhilaration, but from a felt exhaustion about policies oriented and focusing only on women. This exhaustion was explicitly expressed after the talk, when the HR team (all female) participated in the panel discussion. The discussion revolved around complaints and strategies they had to use to get the managers to send their (women) team members to attend the panel in order to show employee participation, since two speakers were from a client firm based in Norway that was visiting the Indian team around that time. During that time, another member of the team P, shared her exhaustion that 'we don't need any more policies oriented towards women, there are enough women in workforce now', an observation that she also shared with the speaker. P's response to the current 'women in science' policies is in stark contrast to R's response who had seen worse days, an experience which is inaccessible to $\mathrm{P}$ working in an industry that saw an influx of middle-class women in 1990s. However, I argue 
that both responses are symptomatic of how the discourse and policy around 'women in science' is framed and circulated with a certain emphasis on increasing the number of women as a beginning and a consequent end in itself.

'So much for having more women...'

While doing my fieldwork with organization B, I would often sit down with the HR team for lunch. During one such team lunch, the HR head was concentrating on a news headline flashing on the TV in front of him. There were around 3-4 TV screens in the canteen, placed in different directions. The volume would mostly be low, as the canteen is mostly crowded and noisy during lunch hours. The only time, that I had seen people sit down in groups to watch TV in the canteen was during a cricket match or elections. On other days, the TV usually played in the background without garnering much attention from the employees. That day, however, I saw the HR head concentrate on a newsflash about the recent ICICI Bank loan scam in which the top suspect was Chanda Kochhar, the then managing director and chief executive officer of the Bank. He mentioned, 'So much for having more women at the top and good leadership huh...'. I could not respond immediately to this comment, and he quickly shifted his attention to another conversation happening in the group. However, this was an important field-note to think and reflect upon. The HR head was echoing the general scepticism which never becomes part of any serious study, but is often exchanged and shared in informal conversations. While clearly guilty of conflating the deeds of an individual (woman) and using it to judge the entire group (of women), the scepticism emerges from, and refutes, the argument that more women leaders will lead to good and ethical work-culture, moral practices and even good development. An association, as mentioned previously, is presumed and taken for granted to make the case for increasing participation. Both lines of thought - the scepticism of the HR manager as well as the association between gender equality, diversity and good work-culture promoted by the 'women in science' discourse to legitimize itself become guilty of essentialism, and one-dimensional approach to the problems of 'women in science'.

\section{Exhaustion}

'I didn't want to be a scientist or join scientific organization...'

My request for an interview was finally accepted by Dr $\mathrm{S}$, a senior scientist working in organization A. She was the first senior scientist who had given me permission for a brief interview. For the last three months, I had been interviewing mid-level scientists and technicians, with whom concerns around work/labour echoed more than any 'love' for science or the mysteries of space/universe. As I waited for her, I reminded myself of this phenome- non. The organization had only recently gained much visibility on social media and popular culture with a plethora of movies, stories and series dedicated to it. The women scientists occupying high positions in the organization, and leading many successful missions had become the face of the organization's success. As I sat down in her office, thinking of a one-liner to start the conversation, S suddenly remarked in her shrill voice, 'if you want to know if I always wanted to be a scientist, or if I always wanted to work here, then I am sorry, I did not want to'.

Similarly, my questions during fieldwork about concerns regarding gender diversity, more women in science, and their relationship with science were all dismissed, mocked at or were answered through general statements as 'this is just like any other work', 'this is life, you learn to adjust' by a group of women scientists whom I had met over lunch and tea. Despite being a predominant mood in the workplace, the contemporary currents of 'women in science' discourse do not provide any language to think about the over determined nature of these responses.

'It's just work nothing else...'

The narrative of the mid-level scientific workforce, both men and women, is starkly different. One does not find narratives of achievement or failure, or pride at engaging with science, but simply work, where working in a Government organization is 'less-stressful', secure and comes with incentives which are not available in the private sector, as opposed to the multinational organization $\mathrm{B}$, where workers complained about precarious work conditions. The decision to enter science is not mentioned as a narrative of individual curiosity, passion or choice, but a decision which takes into consideration one's embeddedness in social conditions. For most of my interlocutors, a decision to enter science depended upon certain other conditions such as career/job opportunities, where science is mostly considered a degree with good job market. At times it is not even a decision but something that the parents asked them to do because good marks in science in India are naively associated with 'intelligence'. The interlocutors also mentioned that unlike these days, they were unaware of any other career paths in other disciplines. The decision to enter science then was a result of parental pressure, social values or lack of other options.

The 'women in science' discourse which associates women in science with participation, empowerment, diversity and access fails to account for these conditions in which most middle-class women actually enter science $^{28}$, i.e. the condition of big science which serves the logic of the market or the state. While the condition of economic independence ensuing from one's participation in the scientific workforce gives a semblance of empowerment, the semblance is always a 'work-in progress' as it is forever aligned with the ups and downs of the development regime. This overdetermined nature of one's reality is manifested affectively among the women 
scientists as either 'exhaustion' or 'scepticism' vis-à-vis both the scientific work as well as the initiatives in science, such as 'women in science'.

\section{Conclusion}

This paper has argued that the 'women in science' problematic is framed in terms of numbers, representation and a linear framework that limits the question of women's work in science to empowerment and development. Through an account of the experience of women scientists, the paper has suggested that these associations produce two simultaneous affects of 'scepticism' and 'exhaustion'. These two affects result from the complexities and over determined nature of experience of working in science which is often ordinary and not exceptional as it is made out to be within the 'women in science' discourse. Acceptance of this ordinariness will allow the 'women in science' discourse to interrupt and interrogate the relation between science and social which is otherwise foreclosed by the current framework.

Conflict of interest: The doctoral thesis is supported by a funding from Tata Consultancy Services, India.

Ethical declaration: All interviews were conducted under informed consent. The names of the participants and the organizations have been anonymized.

1. Man and Woman. Curr. Sci., 1935, 4, 263-264.

2. Ellis, H., Man and Woman: A Study of Human Secondary and Tertiary Sexual Characters, London, W. Heinemann Ltd., 1934.

3. Sharma, Shobhana, Career of women scientists. Curr. Sci., 1995, 68, 24-26.

4. Rao, Sumathi, Women scientists: a contradiction in terms? Curr. Sci., 1999, 76, 24-26.

5. Gupta, Archana, Opportunities for women in science - the CSIR (extra mural re-search) experience. Curr. Sci., 1997, 72, 549-551.

6. Balaram, P., Women in science. Curr. Sci., 1999, 77, 1565-1566.

7. Godbole, R. M., Women in science. Curr. Sci., 1999, 77, 1567.

8. Gupta, N., Kemelgor, C., Fuchs, S. and Etzkowitz, H., Triple burden on women in science: a cross-cultural analysis. Curr. Sci., 2005, 89, 1382-1386.

9. Bal, V., Nowhere near the glass ceiling. Econ. Polit. Wkly, 2004, 39, 3647-3653

10. Gupta, N. and Sharma, A. K., Patrifocal concerns in the lives of women in academic science: continuity of tradition and emerging challenges. Indian J. Gend. Stud., 2003, 10, 279-305.
11. Kurup, Anitha, Mathew, Leya and Singh, Taniya, Taking the next steps (Meeting report on NIAS' collaboration with women in STEM in India). Curr. Sci., 2017, 112, 1986-1987.

12. Gregg, M. and Seigworth, G. J., An inventory of shimmers. In The Affect Theory Reader, Duke University Press, Durham, NC, USA, 2010, pp. 14-15.

13. Briggs, C. L., Introduction. In Learning How to Ask: A Sociolinguistic Appraisal of the Role of the Interview in Social Science Research, Cambridge University Press, New York, USA, 1986, pp. $1-30$.

14. Kumar, N. and Burton, A. M. (eds.), Women and Science in India: A Reader, Oxford University Press, New Delhi, 2009.

15. Gupta, N., Perceptions of the work environment: the issue of gender in Indian scientific research institutes. Indian J. Gender Stud., 2016, 23, 437-466.

16. Subramaniam, B., Ghost Stories for Darwin: The Science of Variation and the Politics of Diversity, University of Illinois Press, Urbana, Illinois, USA, 2014.

17. Association of Academies of Sciences in Asia, Women in Science and Technology in Asia, Panmun Education, Gyeonggi-Do, 2015.

18. Godbole, R. M. and Ramaswamy, R., Women scientists in India. In Women in Science and Technology in Asia, Panmun Education, Gyeonggi-Do, 2015, pp. 7-84.

19. Mazumdar, V. and Sorkar, L., Towards Equality: Report of the Committee on the Status of Women in India, Government of India Press, New Delhi, 1974.

20. Bhatt, Ela R. and Armaity S. Desai, Shram Shakti: Report of the National Commission on Self-Employed Women and Women in the Informal Sector, Government of India Press, New Delhi, 1988.

21. Krishnaraj, M., Women and Science: Selected Essays, Himalaya Publishing House, Bombay, 1991, 1st edn.

22. Poonacha, V. and Gopal, M., Women and science: an examination of women's access to and retention in scientific careers, SNDT Women's University, Mumbai, 2004.

23. Godbole, R. M. and Ramaswamy, R., Lilavati's Daughters: The Women Scientists of India, Indian Academy of Sciences, Bangalore, 2008.

24. Swarup, A. and Dey, T., Women in science and technology: an Indian scenario. Curr. Sci., 2020, 119(5), 744-748.

25. Sur, A., Dispersed Radiance: Caste, Gender, and Modern Science in India, Navayana, New Delhi, 2011.

26. Krishna, S. and Chadha, G., Feminists and Science: Critiques and Changing Perspectives in India Vols 1\&2, Sage, 2017.

27. Subramanian, J., Perceiving and producing merit: gender and doing science in India. Indian J. Gender Stud., 2007, 14, 259-284.

28. Sundararaman, I., 'World would move ahead!': exploring the learning of science and aspirations in the urban context through a case study. Cult. Stud. Of. Sci. Educ., 2020, 15, 775-792.

Received 14 May 2020; revised accepted 12 January 2021

doi: $10.18520 / \mathrm{cs} / \mathrm{v} 120 / \mathrm{i} 11 / 1679-1685$ 